일 반논문-09-14-6-02

\author{
호환성을 고려한 모바일 방송용 서비스가이드 개발 \\ 김 준 환 $)^{\ddagger}$, 장 성 만 ${ }^{\mathrm{a})}$, 정 신 일 ${ }^{\mathrm{b})}$, 경 일 수 ${ }^{\mathrm{b})}$, 김 현 순
}

\title{
Development of Service Guide for Mobile Broadcast Considering Interoperability
}

\author{
Junhwan Kim $^{\text {a) }}$, Sung-man Jang ${ }^{\text {a) }}$, Shin-Il Jeong ${ }^{\text {b) }}$, Il-Soo Kyung ${ }^{\text {b) }}$, and Hyun-Soon Kim ${ }^{\text {b) }}$ \\ 요 약
}

최근 모바일 방송 표준 중 전송계층과 서비스계층 사이에 IP계층이 존재하는 DVB-IPDC, OMA-BCAST와 같은 표준이 상용화 되었다. 특히 OMA-BCAST는 IP 추상계층을 통해 여러 전송계층과 인터페이스가 가능하다. 이런 모바일 방송 표준에서 사용자 인터페이스와 관련된 중요한 부분인 서비스가이드는 표준별로 서로 다른 스키마를 가지며 복잡한 구조를 가진다. 스키마가 호환 되지 않아 한 종류 이상의 서비스계층을 지원하고자 하는 단말에서는 표준별로 별도로 서비스계층을 구현해야 한다. 본 논문에서 는 기존 모바일 방송 표준인 DVB-IPDC와 OMA-BCAST와의 호환성을 고려하면서도 기본적인 사용자 시나리오를 만족할 수 있 는 간결한 서비스가이드 스키마를 개발하였다. 개발된 스키마는 독립된 서비스가이드 스키마로 사용될 수 있고, 기존 모바일 방송 클라이언트 통합 환경에도 응용될 수 있다.

\section{ABSTRACT}

Recently mobile broadcast standards that have IP layer between transport layer and service layer such as DVB-IPDC, OMA-BCAST have been commercialized. Specially, IP abstract layer of OMA-BCAST makes it possible to interface diverse transport layers. Service guide, that is important for user interface, of these mobile broadcast standards has complex structure and heterogeneous schema. ESG schema is not interoperable, therefore terminals should have various implementations of service layer to support more than one service layer at a time. In this paper, not only for enabling interoperability of DVB-IPDC and OMA-BCAST but for supporting basic scenarios of mobile broadcast, simple ESG schema was developed. This new schema can be used as an independent ESG schema, especially for the integrated mobile broadcast middleware environment.

Keyword : ESG (Electronic Service Guide), Mobile Broadcast, IPDC, DVB-H, OMA-BCAST

\section{I. 서 론}

최근 모바일 플랫폼에서 매출 증대를 위한 킬러콘텐츠로

a) (주)더블유알지

WRG

b) 한국방송공사

KBS

\# 교신저자 : 김준환(james.kim@wrg.co.kr)

· 접수일(2009년7월21일), 수정일(2009년9월29일),게재확정일(2009년10월28일)
모바일 TV에 대한 관심이 증가하고 있다. 모바일 방송을 서비스하기 위하여 한국의 DMB, 유럽의 DVB-H(Digital Video Broadcasting - Handheld), 미국의 MediaFLO 등 전 세계적으로 각 지역별, 상황별로 서로 다른 표준이 사용되 고 있다. 특히 유럽에서는 서비스계층 관련 표준 DVB$\mathrm{IPDC}$ 와 OMA-BCAST가 공존하여, 이탈리아에서는 DVB$\mathrm{H}$ 가 네덜란드, 스위스, 오스트리아 등에서는 $\mathrm{OMA}-$ 
BCAST가 상용화 된 바 있다. 모바일 방송 규격을 크게 전송계층과 서비스계층으로 나누어 볼 때, 서비스계층에 서 사용자 인터페이스를 위한 핵심 규격인 OMA-BCAST (Open Mobile Alliance Mobile Broadcast Service Enabler Suite)의 $\mathrm{SG}$ (Service Guide) ${ }^{[1]}$ 와 DVB-IPDC(Digital Video Broadcasting - IP Datacasting)의 ESG(Electronic Service Guide) ${ }^{[2]}$ 는 서로 다른 스키마를 가진다.

이러한 환경에서 모바일 방송 클라이언트에서는 최소한 의 하드웨어를 사용하여 최대한 다양한 서비스를 제공하고 사용하기 위해 하나의 칩에 수신 기능과 멀티미디어 기능 을 통합하여 단일 단말에서 다양한 모바일 TV 규격을 지원 하려는 요구가 있다. 이때, 각 표준이 제공하는 서비스가이 드 데이터모델에 의존하는 미들웨어와 응용프로그램을 작 성하게 되면, 각 표준별로 별도의 미들웨어를 작성해야 하 고 단말에서의 응용프로그램 작성을 위한 부담이 커지게 된다. 만일, 사업자나 단말사 입장에서는 수신 칩, 멀티미디 어 칩 기능을 포괄한 최소한의 관련 하드웨어와 미들웨어 만을 탑재하여 다수개의 표준을 지원할 수 있다면, 개발 비 용을 절감하고 개발 기간을 단축할 수 있다. 예를 들어, 서 비스계층 구현을 위한 미들웨어에서 DVB-H와 OMA$\mathrm{BCAST}$ 를 동시에 지원하게 되면 개발 비용 절감과 기간 단 축이 가능하다. 더욱이 OMA-BCAST는 BCMCS(Broadcast Multicast Services), MBMS(Multimedia Broadcast Multicast Service), DVB-H 적응(adaptation) 규격을 제공하므 로 전송계층으로 DVB-H를 사용하는 것이 가능한데, 이 러한 경우 서비스계층을 구현한 미들웨어만을 DVB-IPDC, OMA-BCAST 공용으로 개발 가능하다면, 두 가지 서비스 를 모두 제공할 수 있다.

본 논문에서는 이러한 문제점들을 해결하기 위해 크게 두 가지를 제안한다.

첫째, 모바일 방송 서비스가이드를 위한 새로운 스키마 를 제안한다. 즉, OMA-BCAST나 DVB-IPDC 스키마와 호 환성을 갖고 이들 스키마보다 간략하면서도 기본적인 유즈 케이스(Use Case) ${ }^{[4]}$ 들을 만족할 수 있는 스키마를 설계하 였다.

둘째, 제안된 스키마를 활용하는 공통 인터페이스를 소 개한다. 즉, 제안된 스키마를 기반으로 하여 미들웨어 종류
에 상관없이 공용으로 사용될 수 있는 공통 인터페이스를 작성하였는데, 개발된 스키마와 공통 인터페이스는 OMA$\mathrm{BCAST}$ 와 DVB-IPDC의 공통 미들웨어 구현에 활용될 수 있다.

본 논문의 구성은 다음과 같다. 2장에서는 서비스가이드 의 개요 및 기존 서비스가이드의 비교 분석 사항을 제공하 며, 3장에서는 제안된 새로운 스키마에 대해 기술하고, 4장 에서는 이 스키마를 활용하는 공통 인터페이스에 대해 기 술하며, 5 장에서는 스키마와 공통 인터페이스 검증을 위해 수행한 실험에 대해 서술한다.

\section{II. 기존 서비스가이드의 개요 및 비교}

$\mathrm{ESG}^{[2]}$ 혹은 $\mathrm{SG}^{[1]}$ 는 디지털 비디오 방송에서 가능한 모 든 서비스의 정보를 제공해 주는 수단이다. OMA-BCAST 는 SG, DVB-IPDC에서는 ESG라는 용어를 사용하는데 본 절에서는 편의상 $\mathrm{ESG}$ 로 통칭하기로 한다. $\mathrm{ESG}$ 는 $\mathrm{TV}$ 프로그램의 스케줄 정보와 장르 같은 단순한 정보만을 제공할 수 있었던 EPG(Electronic Program Guide)의 한계 를 벗어난 것이다. $\mathrm{ESG}$ 데이터 모델의 인스턴스는 XML (eXtensible Markup Language) 기반의 텍스트로 구성되 어 있고, 전송 용량을 줄이기 위해 BIM(Binary format for metadata), GZIP(GNU zip) 등으로 압축된 데이터가 FLUTE (File Delivery over Unidirectional Transport) 프로토콜 ${ }^{[6]}$ 을 사용하여 IP 데이터캐스팅 방식으로 전달된다. 기본적으로 $\mathrm{ESG}$ 는 특정 서비스 제공자(Service Provider)로부터 이용 가능한 서비스의 목록과 각 서비스들에 관한 세부 정보들 을 포함한다. 세부 정보란, 서비스의 이름이나, 서비스의 장 르와 같이 서비스와 직접 연관된 정보부터, 서비스 내에 어 떤 프로그램들이 편성되어있는가와 같이 하위분류에 대한 정보까지 포함된다. 또한 $\mathrm{ESG}$ 는 시작시간과 종료시간, 프 로그램 이름 등 각각의 프로그램에 대한 상세 정보를 포함 한다. ESG 데이터는 사용자가 모바일 TV를 사용할 때 가 장 처음 접하는 데이터로써 원하는 서비스와 콘텐츠를 선 택할 수 있도록 하고 각종 양방향 데이터(Inter- activity Data)에 접근할 수 있는 인터페이스(Interface)도 제공한다. 
그림 1은 모바일 방송 수신기의 서비스가이드 다운로드 절 차로 DVB-H 전송 시스템, 서비스계층을 구현한 미들웨어, 단말 사용자까지 데이터가 전달되는 과정을 보여준다.

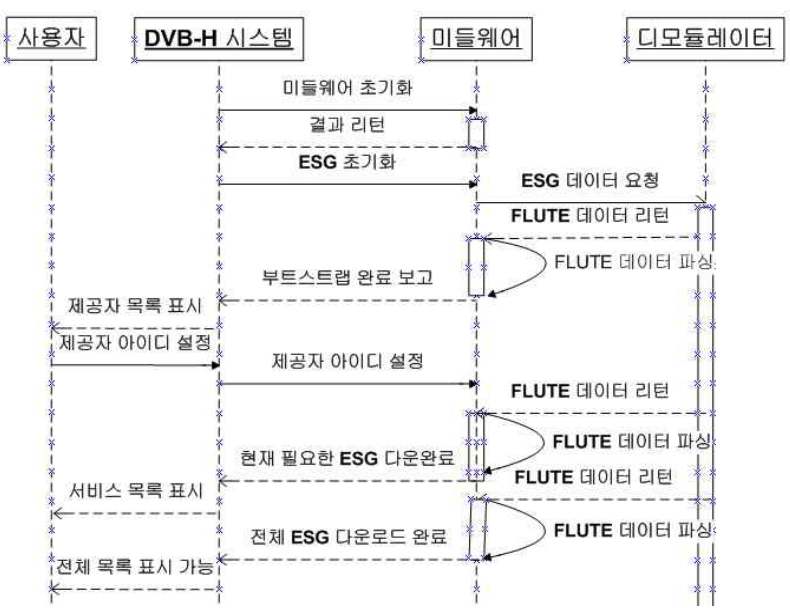

그림 1. 모바일 방송 수신기의 서비스가이드 다운로드 절차

Fig. 1. Service Guide Download Procedure on Mobile Broadcast Terminal

기존 연구로는 MPEG(Moving Picture Experts Group)-7 을 활용하여 $\mathrm{ESG}$ 스키마로 사용한 연구 ${ }^{[7]}$, 개인화 된 (Personalized) ESG용 스키마를 제작한 연구 ${ }^{[8]}$ 와, 대표적인 $\mathrm{ESG}$ 제공업체 중 하나인 Expway에서 개발한 $\mathrm{FastESG}^{[9]}$
사례가 있다. 기술적으로 구체적인 세부 사항까지 유사한 연구는 아직 이루어지지 않았으며, 그러한 연구는 다수개 의 표준을 지원하는 단말에서 필요한데, 일반적으로 한 나 라에서는 하나의 표준을 사용하는 경우가 많고 다른 표준 을 사용한다고 해도, 다수개의 서비스계층의 표준은 표준 자체가 다르기 때문에 공통 미들웨어의 개발이 쉽지 않다. 본 연구의 범위인 OMA-BCAST와 DVB-IPDC는 서비스가 이드 부분만 다르고 프로토콜이 공통부분이 많으며, 두 개 의 서비스 계층을 위한 공통의 전송 계층으로 DVB-H 망의 사용이 가능하기 때문에 ${ }^{[10]}$, 모바일 방송 표준의 사용 측면 에서 특수한 경우라고 볼 수 있다.

단말에서는 다운로드 된 서비스가이드를 사용하여 사용 자가 원하는 서비스를 선택할 수 있는 초기 사용자 인터페 이스를 제공한다. 케이블 방송과 같이 이전에 보던 채널을 바로 재생하는 시나리오도 있을 수 있으나, 이런 경우에도 서비스가이드에 포함된 정보를 이용하기 위한 초기 화면 구성은 필요하다. 이와 같은 채널 정보를 포함한 초기 화면 구성을 위해서는 송출 가능한 채널 번호와 채널 이름, 그리 고 각 채널에서 방송중인 프로그램 이름 및 정보가 필요한 데, 이 정보는 DVB-H 서비스가이드에서 서비스 리스트 질 의, 시간에 따른 이벤트 질의, 관련 콘텐츠 정보 질의 등의 작업을 통해서 얻을 수 있다.
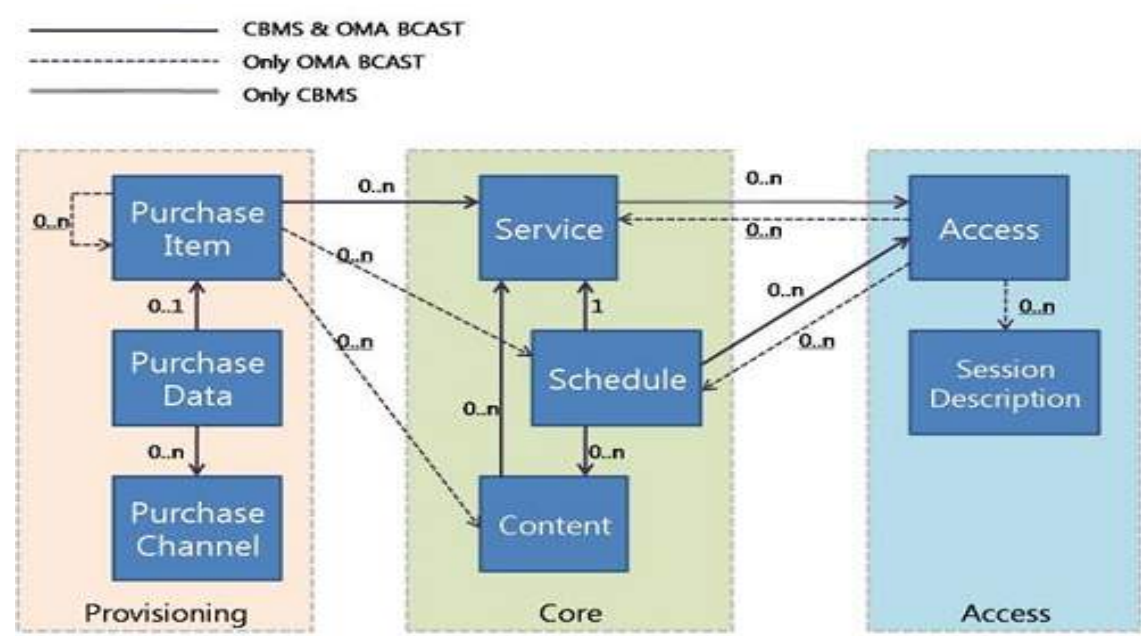

그림 2. DVB-IPDC와 OMA-BCAST(BMCO(Broadcast Mobile convergence) 프로파일 ${ }^{[3]}$ ) 서비스가이드 스키마 비교 Fig. 2. Comparison of Service Guide Schema between DVB-IPDC ESG and OMA-BCAST(Bmco Profile) SG 
$\mathrm{DVB}-\mathrm{IPDC}$ 와 OMA-BCAST와 같이 서비스계층 표준이 달라, 다수개의 표준을 지원해야 하는 경우에는 이를 미리 고려해 주어야 하는데, 서비스가이드의 경우 스키마가 다 르기 때문에 공통부분과 그 외의 부분으로 나누어 인터페 이스를 설계하는 것이 필요하다. 그림 2는 모바일 $\mathrm{TV}$ 표준 인 DVB-IPDC와 OMA-BCAST의 스키마를 비교한 것으로 데이터 모델을 비교한 결과는 다음과 같다.

- DVB-IPDC에서는 ScheduleEvent로부터 Content로 참 조가 없다.

- BCAST에서는 Content와 Access에서 Service를 참조 한다. IPDC에서는 그 반대이다.

- IPDC는 ScheduleEvent에서 Acquisition으로 참조를 제공하는데, BCAST에서는 그렇지 않다.

- BCAST에서는 ServiceBundle로부터 Schedule 또는 Content로 참조를 허용한다.

- IPDC에서는 Purchase로부터 PurchaseChannel로 참조 가 선택적인데, $\mathrm{BCAST}$ 에서는 필수요소이다.

- IPDC에서는 Purchase로부터 ServiceBundle로 참조가 선택적인데, $\mathrm{BCAST}$ 에서는 필수요소이다.

DVB-IPDC ESG ${ }^{[2]}$ 에서는 미리보기(Preview) 엔터티가 없고, $\mathrm{OMA}-\mathrm{BCAST} \mathrm{SG^{[1] }}$ 에는 미리보기가 있는데, 단말에 서는 서비스가 미리보기 정보의 포함여부를 사용자에게 알 려주어 보여주기 위한 미리보기 엔터티를 식별할 수 있어
야 한다. PPV(Pay Per View)서비스를 프로모션 하는 방법 중 하나가 미리보기가 지원되는 서비스를 탐색하는 것이다. 기존의 OMA-BCAST SG의 전체 스키마는 단일 프래그 먼트의 속성 개수, 예를 들어, 'Access' 프래그먼트의 엘리먼 트와 속성의 총 개수의 합이 100 개가 넘을 정도로 복잡하다. 따라서 실제 사용될 때는 $\mathrm{BMCO}$ 프로파일 ${ }^{[3]}$ 등 이미 정의 된 전체스키마의 부분집합이 사용되는 경우가 많고, 이런 프로파일을 사용하지 않을 경우 자체적인 부분집합의 정의 가 필요할 수 있다. 이에 반하여 DVB-IPDC ESG 스키마는 간단한 것이 장점이지만, 인터액티비티 데이터나 미리보기 데이터 등 새로운 기능 지원을 위한 확장이 필요하다.

\section{III. 서비스가이드 스키마 개발}

\section{1. 개요}

본 논문에서는 기존 스키마의 복잡성과 비호환성을 해결 하기 위해 간결성과 호환성을 가지며 기본적인 시나리오 수행이 가능한 스키마를 설계하였고, 이 스키마를 사용하 여 미들웨어와 어플리케이션을 개발할 때 사용될 수 있는 공통 인터페이스를 개발하여, 표준의 종류에 관계없이 어 플리케이션 개발이 가능한 구조를 제안하였다. 제안한 방 법의 검증을 위해, OMA-BCAST와 DVB-IPDC의 서비스 송신에 사용되는 실제 스트림을 녹화한 후, IP 데이터그램

표 1. 서비스가이드 스키마 개발 과정

Table 1. Development process of Service Guide

\begin{tabular}{|c|c|c|c|}
\hline 순번 & 항목 & 항목의 명세 & 서술된 위치 \\
\hline 1 & 메타데이터 범위 & 기본 유즈케이스를 만족하는 수준 & \multirow{3}{*}{ 3.2절 } \\
\hline 2 & 카테고리 정의 & $\begin{array}{l}\text { 서비스 및 콘텐츠 중심의 접근 ( DVB TM CBMS-1152 참조) } \\
\text { 서비스, 콘텐츠, 구매, 액세스 (프로그램의 위치) }\end{array}$ & \\
\hline 3 & 프래그먼트 조사, 취합 & MPEG-7 Part 5, TV-Anytime 등의 스키마 분석 & \\
\hline 4 & CORE 스키마 & 5 개의 프래그먼트 제안 & 3.3절 \\
\hline 5 & 유즈케이스 적합성 & CORE 스키마의 구조설계의 유즈케이스에 적합성 고려 & 3.4절 \\
\hline 6 & 속성 배치 & 엘리먼트, 속성들로 취사선택 및 배치 & \multirow{3}{*}{ 3.5절 } \\
\hline 7 & 참조 관계 & 각 프래그먼트의 식별자와 타 프래그먼트에서 참조 관계를 고려 & \\
\hline 8 & 호환성 & $\begin{array}{l}\text { 기존 메타데이터 타입을 응용할 것인지 혹은 단순 타입을 사용하여 복합 } \\
\text { 객체(엘리먼트)를 정의할 것인지 등을 정의 }\end{array}$ & \\
\hline
\end{tabular}


수준에서 수정하여 개발된 스키마를 따르는 $\mathrm{ESG}$ 를 삽입하 고, 이 스트림을 공통 인터페이스를 통해 접근하여 $\mathrm{ESG}$ 의 서비스 정보와 콘텐츠 정보를 출력하는 실험을 수행하였다.

표 1은 모바일 방송의 기본적인 유즈케이스를 만족하면 서 호환성을 갖는 스키마 개발 절차이다. 사용자가 $\mathrm{ESG}$ 를 브라우징 하여 채널을 선택하고 실제 모바일 방송 서비스 를 시청하는 가장 일반적인 시나리오를 적용하여 초기 데 이터 모델을 만들어 프래그먼트를 추가하고 이를 다시 실 제 유즈케이스 ${ }^{[4][5]}$ 에 적용가능한지 검증하는 과정을 거쳐 스키마를 정제 해 나간다. 이 과정은 DVB-IPDC의 $\mathrm{ESG}$ 스 키마 개발과정과 유사하다. 3.2절에서는 3단계까지, 3.3절 에서는 4단계, 3.4절에서는 5단계, 그리고 3.5 절에서는 나 머지 단계를 설명한다.

제안된 서비스가이드 기술 형식은 프래그먼트들이 단 순타입과 이를 가지는 복합 엘리먼트들을 가지는 OMA$\mathrm{BCAST}$ 형식을 따르며, DVB-IPDC에서와 같이 TVAnytime 등의 외부 타입을 사용하지는 않는다. 기존 스키 마와의 가장 큰 차이점은 간결하다는 것인데, 현재의 스키 마가 복잡하기 때문에 이 중에서 가장 많이 사용되는 핵심 엘리먼트만으로 호환성 있는 스키마를 구성하고자 한 것 이다.

\section{2. 카테고리 정의 및 타 스키마 참조}

(1) 메타데이터 범위 : 먼저 메타데이터의 대략적인 범위 를 결정하는 단계이다. 본 단계는 다음 단계를 위한 범위의 정의로, 최종 스키마 수준의 메타데이터 범위 를 정할 필요는 없다. 본 논문의 목적이 호환성 있고 간결한 스키마의 설계이므로, 초기 메타데이터의 범 위는 기존 모바일 방송에서 사용하는 메타데이터의 부분집합이라고 보았으며, 개발 단계를 거치면서 속 성이나 엘리먼트들이 추가, 수정, 보완되었다. 메타데 이터 범위를 결정하기 위해서 첫째로 DVB-IPDC와 OMA-BCAST의 서비스가이드 엘리먼트와 속성들을 정리하고, 공통으로 사용하는 속성들을 선별하였고, 둘째로 DVB-IPDC 유즈케이스 규격 문서 ${ }^{[4]}$ 에서는 4.3절의 $\mathrm{ESG}$ 시작, 서비스 목록의 출력, 서비스와 관
련된 정보 관리 등 3 개의 유즈케이스와 4.1절의 인터 액티비티, 4.2절의 액세스 컨트롤 등 기본적인 유즈케 이스를 참조하였다. OMA-BCAST의 유즈케이스드를 고려하지 않은 것은 DVB-IPDC의 경우 하나의 유즈 케이스는 유즈케이스의 카테고리를 나타내어 다수개 의 유즈케이스를 의미적으로 포함할 수 있으나, OMA$\mathrm{BCAST}$ 의 경우 하나의 유즈케이스는 하나의 사례를 표현하는 형식이기 때문이다 ${ }^{[4][5]}$.

(2) 카테고리 정의 : 두 번째는 카테고리를 정의하는 단 계이다. 본 논문에서는 프래그먼트의 카테고리를 채 널을 나타내는 서비스와 프로그램을 표현하는 콘텐 츠, 실제 $\mathrm{A} / \mathrm{V}$ 와 연동하기 위한 액세스 그리고 구매를 위한 프래그먼트, 네 가지를 고려하였다. 참고로, TVAnytime $^{[7]}$ 에서는 프로그램, 프로그램 위치(Pro- gram Location), 프로그램 그룹(Program Group)으로 초기 카테고리를 정의하였고, DVB-IPDC에서는 서비스 및 콘텐츠 중심으로 서비스(Service), 콘텐츠(Con- tent), 스케줄(Schedule)의 카테고리를 정의하였다.

(3) 프래그먼트 조사, 취합 : 세 번째 단계는 MPEG-7 $\operatorname{Part5}^{[12]}, \mathrm{TV}-A n y t i m e^{[11]}$ 등 모바일 방송에 국한되지 않은 방송 표준과 멀티미디어 표준을 비교하여 이를 스키마 작성에 반영하는 단계이다. DVB-IPDC ESG 데이터모델은 TV-Anytime을 기반으로 하였기 때문 에 기본 엔터티와 속성들이 유사한 것들이 많이 존재 하는데, 예를 들어 서비스 프래그먼트의 속성인 'ServiceName', 'ServiceDescription', 'ServiceLogo', 'ServiceLanguage' 등이 TV-Anytime의 'ServiceInformationType'에서 가져온 것들이다.

\section{CORE 스키마 생성}

본 연구에서 제안하는 스키마를 위한 초기 데이터 모델 인 $\mathrm{CORE}$ 스키마는 그림 3과 같이 다섯 개의 프래그먼트로 구성되고, 각 프래그먼트는 식별자 (ID)를 가진다. 서비스 와 콘텐츠가 공통으로 가지는 'PreviewData'는 미리보기를 위해 사용되는 엘리먼트이며 'RelatedMaterial'은 본 서비 스, 콘텐츠와 연관된 정보들에 대한 연결수단을 제공한다. 
스키마 중 'Service'와 'Content' 프래그먼트는 OMA$\mathrm{BCAST} \mathrm{SG}$ 와 DVB-IPDC ESG에 공통으로 존재하는 속성 들을 중심으로 구성하였는데, DVB-IPDC ESG의 엘리먼트 와 속성 개수가 더 적기 때문에 결과적으로 DVB-IPDC $\mathrm{ESG}^{[2]}$ 와 유사하다. 'Service' 프래그먼트의 경우, DVBIPDC의 'Service' 프래그먼트의 엘리먼트와 속성 중 Name, Number, Description, Type, Genre 엘리먼트 등과 ID 속성 등 OMA-BCAST SG${ }^{[1]}$ 의 'Service'프래그먼트에도 존재하 는 엘리먼트들을 스키마에 포함시켰으며, FreetoAir, ClearTo Air등 기본적인 정보를 나타내는 속성과 간단한 정보 링크를 위해 사용되는 RelatedMaterial 엘리먼트를 포함하 였다. 'Content' 프래그먼트의 경우, DVB-IPDC의 'Content' 프래그먼트의 엘리먼트 중 Title, Mediatitle, Synopsis, ContentType, ParentalGuidence, RelatedMaterial 엘리먼 트와 ID 속성 등을 그대로 수용하였고, 다만 FreeToAir,
ClearToAir 정보를 명확히 하기 위해 포함시켰으며, 'Schedule' 프래그먼트를 가지지 않는 대신 'Content'에 시작과 끝 시간 정보를 나타내는 엘리먼트를 추가하였다. 'Interactivity'프래그먼트의 경우 OMA-BCAST의 'InteractivityData' 프래그먼트에서 일부 속성들만 선택하여 구성하였으며, 'Access'프래그먼트의 경우는 DVB-IPDC의 'Aquisition' 프 래그먼트에서 일부 속성들만 선택하여 구성하였다. 'Purchase' 프래그먼트는 OMA-BCAST SG와 DVB-IPDC에서 각각 3 개씩의 구매 관련 프래그먼트를 가지는데 이 3 개를 통합하여 하나의 프래그먼트로 구성하였다.

제안된 스키마가 기존 스키마와 다른 점은 다음과 같다.

첫째, DVB-IPDC에와 OMA-BCAST에서는 구매 관련 프래그먼트가 3 개인데 본 논문에서는 구매 관련 프래그먼 트를 1 개로 통합 관리한다. 즉, DVB-IPDC의 'Service Bundle', 'Purchase', 'Purchase channel'와 OMA-BCAST의

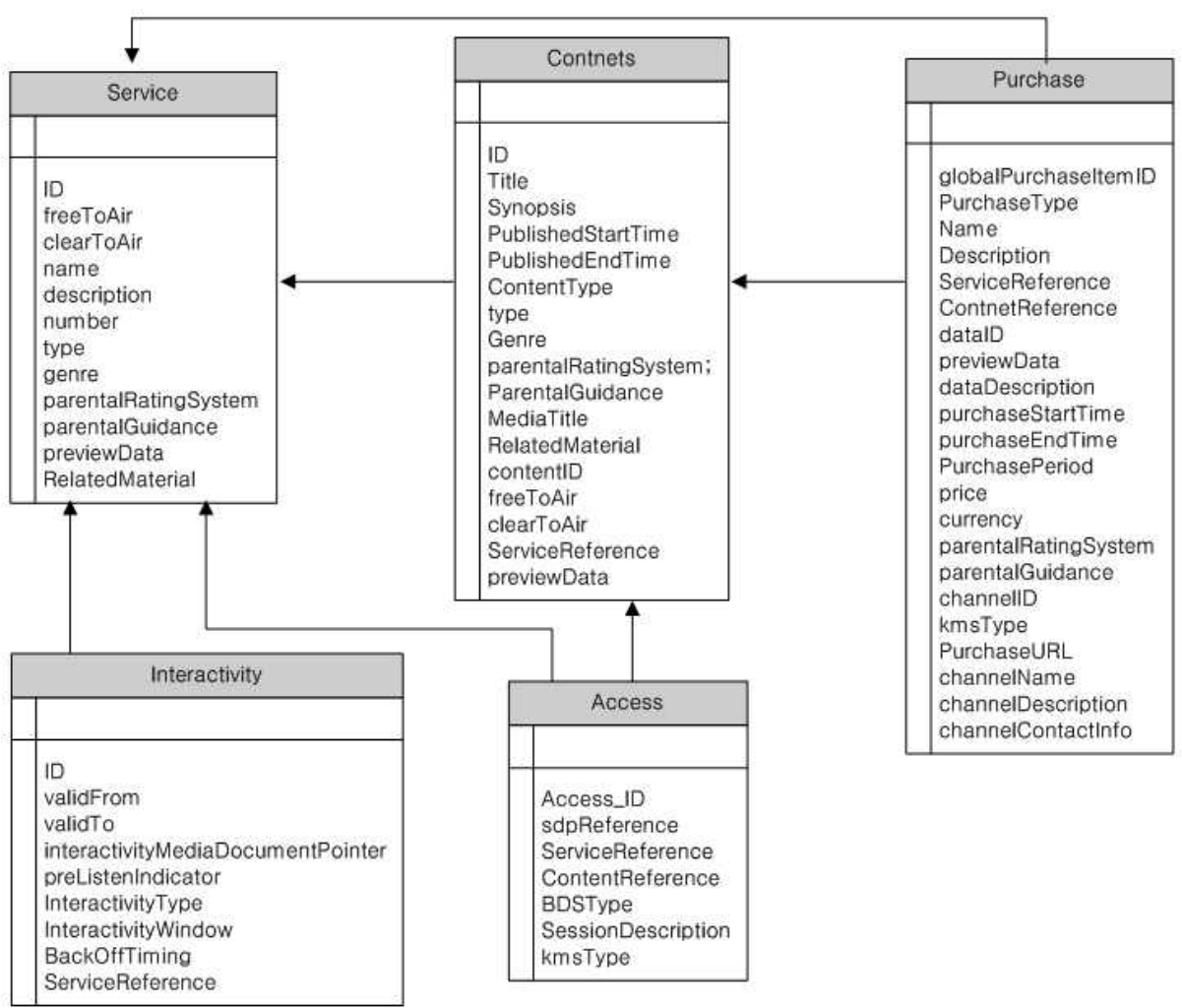

그림 3. 제안된 서비스가이드 스키마

Fig. 3. Proposed Service Guide Schema 
'Purchase item', 'Purchase data', 'Purchase channel'이 다루 는 의미들을 'Purchase'라는 프래그먼트에서 통합 관리한다. 이것은 제안된 스키마의 'Purchase' 프래그먼트가 구매채널 정보를 속성으로 가지며, 단일 구매 아이템 혹은 구매 아이 템 리스트를 엘리먼트로 포함함으로써 가능하다.

전체 서비스가이드 스키마가 OMA-BCAST에서는 크게 (1) 구매 부분 혹은 Provisioning, (2) 'Service'와 'Content'를 포함하는 'Core'부분, 오디오/비디오에 관한 링크를 제공하 는 (3) Access부분의 세 부분으로 나누어져 있고, 이것은 DVB-IPDC에서도 유사하다. 이중에서 구매 부분과 Core부 분간의 링크는 DVB-IPDC의 경우에는 'ServiceBundle'과 'Service' 간의 참조 관계 단 하나이며, OMA-BCAST에서 도 Core부분과 링크되는 프래그먼트는 'PurchasItem' 단 하 나이다. 또한, 구매부분과 Access부분간의 참조는 두 표준 에서 모두 존재 하지 않는다. 따라서 구매 부분의 세 가지 엔터티를 하나로 통합하더라도 타 부분과의 참조 관계에서 는 의미가 축소되지 않는다. 구매 부분의 세 가지 프래그먼 트의 통합을 위해 'PurchasItem' 프래그먼트에 나머지 두 개 의 프래그먼트가 엘리먼트로 속하게 하여 스키마를 간단하 게 하였다.

이때 구매 데이터에 대한 구매 채널 정보가 각 데이터 마다 중복되는 현상이 발생할 수도 있으나, Purchaschan$\mathrm{nel}$ 프래그먼트가 타 프래그먼트보다 상대적으로 간단하고, 실제 상용화 스트림에서의 데이터 량도 많지 않아 문제가 되지 않는다.

둘째, OMA-BCAST에 존재하는 'PreviewData'가 본 스 키마에서는 스키마를 간결하게 하기 위해 프래그먼트로 독립되어 있지 않다. 현재 'PreviewData'가 다양하게 서비 스되고 있지 않고 있으며, 만일 서비스가 되더라도 웹 링 크와 같이 간단한 경우는 'Service'(서비스), 'Content'(콘텐 츠)가 가지고 있는 RelatedMaterial 속성을 할 수도 있으 며 좀 더 복잡한 경우에는, 본 스키마의 중요 프래그먼트에 'PreviewData'를 엘리먼트로 포함하여 이 엘리먼트가 가지 는 'dataDescription' 속성을 사용하여 해당 시나리오를 처리 할 수 있다. 본 스키마에서는 미리 보기 데이터와 로고데이 터 등으로 제한적으로 사용되는 'PreviewData' 프래그먼트 를 따로 독립시키지 않고, 엘리먼트 수준에서 Purchase,
Service, Content 프래그먼트에 포함시켰다.

셋째, 'Schedule'(스케줄) 프래그먼트가 존재 하지 않는 다. 'Schedule' 프래그먼트의 역할은 'Service', 'Content', 'Access'를 연결하여 하나의 이벤트를 표시하는데, 이것은 'Service'와 'Content'의 목록과 각각의 시작, 끝 시간과 참조 관계를 관리함으로써 파악이 가능하다.

스케줄 프래그먼트는 스케줄이 속한 콘텐츠, 인터액티비 티 데이터, 미리보기 등이 조합된 복잡한 시나리오이거나 실시간으로 $\mathrm{SDP}(\mathrm{Session}$ Description Protocol)가 바뀔 때, 또는 스케줄에 따라서 구매가 이루어질 때 등의 시나리오 에서는 필요하지만, 채널리스트에서 프로그램을 선택하고 서비스에 속한 인터액티비티 데이터만 유용한 비교적 단순 한 시나리오에서는 'Service', 'Content', 'Access' 등을 연결 하는 역할 이상을 하지 않기 때문에, 본 스키마에서는 'Service', 'Content'만으로 관련된 정보를 파악할 수 있도록 하였다.

\section{4. 유즈케이스 적합성 검증}

모바일 방송 표준 규격의 제정과정에서 초기에 필요한 작업 중 하나가 규격이 만족해야 할 요구사항들을 정리하 고, 이와 관련된 시나리오들을 기술하여 실제 세부 기능들 이 어떻게 구현될 것인가에 대하여 고려하는 것이다. 이렇 게 정리된 모바일 방송용 가상 시나리오들을 본 논문에서 는 유즈케이스라고 부르며, 기존 표준의 경우 DVB-IPDC 는 독립된 유즈케이스 문서 ${ }^{[4]}$ 로 $\mathrm{OMA}-\mathrm{BCAST}$ 에서는 요구 사항 문서에 기술하였다. DVB-IPDC의 경우 기본적인 유 즈케이스 25 개를 제시하고 이것을 6 개의 분류로 카테고리 화 하였으며, 유즈케이스를 사용한 총 6 개 서비스 예제를 규격에 기술하였다 ${ }^{[4]}$. OMA-BCAST의 경우에는 기능적, 응용적 유즈케이스의 두 개로 분류하고 각 유즈케이스를 $\mathrm{ESG}$, 파일/스트림전송, 서비스보호 등 요구사항들의 카테 고리와 매핑 테이블을 생성하여 각 유즈케이스들이 어떠한 기능과 관련되는지 정리하였다 ${ }^{[5]}$.

본 연구에서는 유즈케이스 적합성 검증을 위해 표2에서 와 같이 DVB-IPDC의 유즈케이스 25개와 OMA-BCAST 의 유즈케이스 22 개 중 9 개를 기본 유즈케이스로 선정하고, 
이를 만족시키는지 검증하였다 ${ }^{[4][5]}$. 유즈케이스 선별 기준 은 현재까지 상용화시 사용된 시나리오와 타 시나리오를 위한 기반이 되는 시나리오들을 중심으로 선택하였다. 서 비스목록을 조회하고 검색하여 프로그램 정보를 보는 것은 시청을 위한 최소한의 시나리오이며, 등록, PPV 구매 및 번들 구매는 더욱 복잡한 구매 시나리오의 기반이 되고, 파 일 다운로드와 인터액티비티 유즈케이스는 리치미디어 서 비스 등의 좀 더 다양한 서비스를 위한 기초가 될 수 있다. 우측의 참조규격 열은 두 개로 나뉘어져 있는데, 각각은 채용한 DVB-IPDC의 유즈케이스 번호와 OMA-BCAST의 유즈케이스 번호를 나타낸다. 기존의 각 규격의 유즈케이 스 중에는 해당 규격 내의 서비스가이드도 만족시키지 못 하는 유즈케이스가 다수 개 존재 한다. 예를 들어, OMA$\mathrm{BCAST}$ 의 '멀티 플레이어 게임' 유즈케이스는 현재 상황에 서 $\mathrm{SG}$ 가 지원한다고 판단하기 힘들다. 따라서 본 논문에서 도 표2에서와 같이 기존 표준의 일부분에서 기본적인 유즈 케이스들을 선정하여 지원하였으며, 표 2 의 3 번째 열에 해 당 유즈케이스들을 제안된 스키마에서 지원하기 위한 프래 그먼트 및 엘리먼트에 관한 설명을 기술하였다.

채널을 선택할 수 있는 'Service' 프래그먼트, 선택된 채널 에서 해당 시간에 방송되는 'Content' 프래그먼트와 이들 서 비스 및 콘텐츠와 관련된 $\mathrm{A} / \mathrm{V}$ 에 대한 정보를 가지고 있는 'Access' 프래그먼트가 있으면 일반적인 TV 시청시나리오 는 가능하다. 'Content'프래그먼트는 'Access' 프래그먼트의 참조를 가지고 있고, 'Access' 프래그먼트는 실제 파일 다운
로드를 위한 $\mathrm{SDP}(\mathrm{Session}$ Description Protocol) 정보를 가 지고 있다. 이때, 채널 목록은 모든 'Service'프래그먼트의 집합을 사용하여 사용자 화면에 표시하면 된다. 서비스, 콘 텐츠의 장르별 시간별 검색을 위해서는 해당 프래그먼트의 장르, 시작시간, 끝 시간 속성을 사용하면 된다. 프로그램과 관련한 상세 정보는 'Content' 프래그먼트의 Description 속 성을 그대로 사용하면 되며, 인터액티비티 관련 정보는 'Interactivity'프래그먼트에 포함된 정보를 사용하면 된다.

OMA-BCAST에는 'PreviewData'라는 미리보기를 위한 전용 프래그먼트가 존재한다. DVB-IPDC에서는 미리보기 를 위한 별도의 프래그먼트를 제공하지는 않고, 각각의 프래그먼트에 대한 설명을 보여주는 정도로 미리보기를 지원하고, 예고편 등의 추가적인 비디오를 위해서는 'RelatedMaterial' 타입을 사용하여 링크를 통해 미리보기를 위 한 자원에 연결하거나, 'ZappingSupport'라는 Classification 스키마를 'Acquisition' 프래그먼트가 엘리먼트로 가짐으로 써 지원한다. 'Service', 'Content', 'ServiceBundle' 프래그먼 트 각각이 'RelatedMaterial' 엘리먼트를 갖고 있다. 'RelatedMaterial' 엘리먼트가 가진 'Howrelated' 엘리먼트 값을 체 크하여 ESG 보조데이터를 사용하여 미리보기용 데이터를 가져온다. 제안된 스키마에서는 'Service', 'Contents', 'Purchase' 프래그먼트에 PreviewData라는 엘리먼트를 사용하 여 미리보기를 지원한다.

구매가 필요한 서비스의 경우 일정 금액을 지불하고 등 록 한 후 서비스를 소비한다. 이를 지원하기 위해서는 구매

표 2. 기본 유즈케이스

Table 2. Basic Use Cases

\begin{tabular}{|c|c|c|c|c|}
\hline 순번 & 유즈케이스 & 제안된 스키마에서 해당 유즈케이스 지원방법 & \multicolumn{2}{|c|}{ 참조규격 $[4][5]$} \\
\hline 1 & 서비스리스트를 사용자 화면에 표시 & Service 프래그먼트들의 리스트를 사용 & 4.3 .2 & 1 \\
\hline 2 & 서비스의 검색 및 분류 (장르별, 시간별) & Service와 Content 에 장르, 시간 정보 사용 & 11 \\
\hline 3 & 서비스 특화 ESG 정보(프로그램 세부정보) & Content 프래그먼트의 Description 정보를 사용 & 4.3 .3 & \\
\hline 4 & 인터액티브와 연관된 콘텐츠의 사용 & Interactivity 프래그먼트를 사용 & 4.1 .3 & \\
\hline 5 & 재핑,채널전환시 그림, 동영상 등 정보제공 & Service, Contents, Purchase의 PreviewData 사용 & 4.6 .1 & 10 \\
\hline 6 & 등록 한 후 서비스를 이용 & Purchase의 PurchasChannel과 price 속성 사용 & 4.2 .3$, & \\
\hline 7 & 프로그램 단위로 구매 (PPV) & Service와 Content에서 Free-To-Air, Clear-To-Air지원 & 4.2 .4 & \\
\hline 8 & 단일 서비스 및 서비스 묶음 구매 가능 & Purchase가 Service의 참조를 여러개 가지는 구조로 가능 & 4.2 .9 & \\
\hline 9 & 파일 다운로드 & Content의 ContentLocation을 FLUTE 세선속성과 같게 & 4.4 .2 & \\
\hline
\end{tabular}


를 할 수 있는 URL 등의 실제 경로가 필요하고, 가격 등 구매 시 필요한 데이터가 필요한데, DVB-IPDC와 OMABCAST에서 모두 'PurchaseChannel' 이라는 이름의 프래그 먼트에서 구매 경로를 제공하고 DVB-IPDC에서는 'Purchase' 프래그먼트에서 그리고, OMA-BCAST에서는 'PurchaseData' 프래그먼트에서 가격정보를 제공할 수 있다. 본 논문의 스키마에서는 'Purchase' 프래그먼트의 E1 수준 엘 리먼트 'PurchasChannel'에서 구매 경로를 제공하고, 'Purchase' 프래그먼트의 E2 레벨 엘리먼트인 'price'에서 가격 정보를 제공한다. 즉, DVB-IPDC와 OMA-BCAST에서는 이 유즈케이스를 만족하기 위해 3 개의 프래그먼트를 사용 하는데, 본 논문에서는 이를 'Purchase'라는 하나의 프래그 먼트로 통합하였다.

구매 시 하나 이상의 서비스를 한꺼번에 구매할 수 있도 록 지원해야 한다. 이를 지원하기 위해서는 구매 시 사용할 수 있는 여러 개의 서비스 묶음을 가진 프래그먼트가 필요 한데, 이를 위해, DVB-IPDC에서는 'ServiceBundle' 프래그 먼트가 'ServiceRef' 엘리먼트를 여러 개 가짐으로써 번들 구매를 지원할 수 있고, OMA-BCAST에서는 'PurchaseItem' 프래그먼트가 'ServiceReference' 엘리먼트를 여러 개 가짐으로써 번들 구매를 지원 할 수 있다. 본 논문의 스키마 에서는 Purchase 프래그먼트가 Service 프래그먼트의 참조 를 여러 개 가지는 구조로 번들 구매를 지원한다.

마지막으로, 파일 다운로드를 위해서는 'Content' 프래그 먼트의 ContentLocation 속성을 FLUTE 세션의 'ContentLocation'과 일치하게 설정하고 이 정보를 사용하면 FLU$\mathrm{TE}$ 프로토콜을 통해 파일 다운로드가 가능하다.

\section{5. 참조관계 및 호환성}

서비스가이드 프래그먼트간의 참조관계는 크게 6 개이다. 'Access' 및 'Purchase'가 각각 'Service'와 'Content'를 참조하 고 있으며, 'Interactivity'와 'Content'가 서비스를 참조하고 있다. 참조 하고 있다는 것은 대상 프래그먼트의 식별자 (ID)를 속성으로 가진다는 것인데, 예를 들어, 'Access'에서 는 'Service'와 'Content'의 식별자를 모두 가지고 있다. 타입의 호환성 측면에서는 DVB-IPDC는 TV-Anytime의
타입들을 그대로 사용하는 것이 존재하며, OMA-BCAST 는 정수, 스트링 등 단순타입만을 사용한다. OMA-BCAST 서비스가이드에서는 복합 객체를 프래그먼트마다 자체적 으로 정의하되, 다른 프래그먼트와 공용으로 사용하지 않 는 방식을 사용하는데, 본 논문에서도 OMA-BCAST의 기 술방법을 사용하였다.

\section{IV. 타 표준 호환성을 위한 일원화 된 인터페이스}

제안된 공통 인터페이스를 위한 기본 데이터모델은 앞에 서 정의된 서비스가이드의 스키마를 사용한다. 공통 인터 페이스를 위해 DVB-IPDC와 OMA-BCAST의 'Service', 'Content'와 그 스케줄 등을 총괄 관리하기 위하여 TV 가이 드 패키지라는 새로운 자료구조를 만들었고, 또한 TV 시청 자체 외에도 중요한 사용자 시나리오인 '구매'와 관련된 데 이터들을 통합해서 다루는 구매가이드 패키지를 만들었다. 4.1절에서 공통 인터페이스 계층 $1,4.2$ 절에서는 공통 인터 페이스 계층 2 를 소개하였는데, 이들의 차이점은 1 계층은 서비스가이드의 프래그먼트를 직접 호출하고 리턴 받는 형 태라면, 2 계층은 1 계층 함수의 조합으로 만들어져서 각각 의 $\mathrm{GUI}$ 장면들과 직관적으로 매핑 될 수 있도록 하여 더 응용프로그램에 가까운 인터페이스라는 점이 다르다.

\section{1. 공통 인터페이스 1계층}

공통 자료구조를 액세스하기 위한 함수들로 'Service', 'Content' 등 각각의 공통자료구조에서 정의한 각각의 자료 구조의 모든 인스턴스들을 가져올 수 있는 함수들을 구현 하였다. 이것은, 표 3 의 '종류'에서 모든 아이템을 리턴 하 는 경우에 해당한다. 그리고 특정 프래그먼트의 식별자(ID) 를 입력으로 주었을 때 출력으로 해당 식별자가 속한 프래 그먼트에 따른 공통자료구조 정보를 가져올 수 있는 함수 들을 구현하였는데, 이것은 표3의 '종류'에서해당 $\mathrm{ID}$ 의 아 이템만 리턴 하는 경우에 해당한다. GetTotalPurchaseItem, GetTotalPurchaseChannel, GetSinglePurchaseItem, Get- 
표 3. 공통 인터페이스를 위한 계층 $1 \mathrm{API}$ 함수

Table 3. Layer 1 API Function for Common Interface

\begin{tabular}{|l|c|c|}
\hline \multirow{4}{*}{ 종류 } & \multicolumn{2}{|c|}{ 인터페이스 } \\
\hline \multirow{4}{*}{ 1. 모든 아이템 } & Get_ALL_EsgProvider & 모든 서비스가이드 제공자들의 목록을 구한다. \\
\cline { 2 - 3 } & GetTotalService & 모든 서비스들의 목록을 구한다. \\
\cline { 2 - 3 } & GetTotalContent & 모든 콘텐츠들의 목록을 구한다. \\
\cline { 2 - 3 } & GetTotalPurchaseltem & 모든 구매 아이템들의 목록을 구한다. \\
\cline { 2 - 3 } & GetTotalPurchase & 모든 구매 관련 데이터들의 목록을 구한다. \\
\cline { 2 - 3 } & GetTotalPurchaseChannel & 모든 구매 채널들의 목록을 구한다. \\
\cline { 2 - 3 } & FindContent & 시작시간부터 경과시간 사이의 콘텐츠를 리턴 한다. \\
\hline \multirow{5}{*}{\begin{tabular}{c|c|} 
2. 해당 ID의 \\
아이템만 리턴
\end{tabular}} & GetSingleService & \\
\cline { 2 - 3 } & GetSingleContent & 주어진 서비스 ID를 가지는 서비스의 정보를 구한다. \\
\cline { 2 - 3 } & GetSinglePurchaseltem & 주어진 콘텐츠 ID를 가지는 콘텐츠의 정보를 구한다. \\
\cline { 2 - 3 } & GetSinglePurchase & 주어진 구매 아이템 ID를 가지는 구매 아이템의 정보를 구한다. \\
\cline { 2 - 3 } & GetSinglePurchaseChannel & 주어진 구매 데이터 ID를 가지는 구매 데이터 정보를 구한다. \\
\cline { 2 - 3 } & 주어진 구매 채널 ID를 가지는 구매 채널의 정보를 구한다. \\
\hline
\end{tabular}

SinglePurchaseChannel의 네 개의 함수는 본 연구의 스키마 를 위해서는 사용되지 않고, DVB-IPDC와 OMA-BCAST 를 공통으로 지원하는 모듈에서 사용된다.

\section{2. 공통 인터페이스 2 계층}

공통 인터페이스 2 계층은 1 계층 함수의 조합으로 이루 어지거나 1 계층 함수의 기능에 약간의 기능이 추가되어 사 업자가 요구하는 사용자화면(Graphical User Interface : GUI) 요구사항을 맞추는데 기본이 되는 함수들을 구현하
였다. 채널별로 프로그램을 나열하기 위해서는 하나의 서 비스와 관련되는 모든 콘텐츠들을 검색할 수 있는 함수가 필요하고, 사용자가 $\mathrm{A} / \mathrm{V}$ 를 시청하기 위해서는 서비스와 연 동되는 $\mathrm{A} / \mathrm{V}$ 의 참조를 구하기 위한 함수도 필요하다. 하나 의 콘텐츠가 여러 개의 세션 디스크립션을 갖는 경우도 발 생하는데, 예를 들어 다중언어를 지원하여 서로 다른 언어 의 콘텐츠와 각각 세션이 연결되는 경우나, 방송망 외에 $3 \mathrm{G}$ 망으로도 $\mathrm{A} / \mathrm{V}$ 가 이용 가능한 경우 등이다. 이때는 하나의 콘텐츠와 연결되는 모든 세션 디스크립션을 구하는 함수가 필요하다.

표 4. 공통 인터페이스를 위한 Layer 2 API 함수

Table 4. Layer 2 API Function for Common Interface

\begin{tabular}{|c|c|c|}
\hline \multirow{4}{*}{ 패키지 조회 및 검색 } & GetTotalPurchaseGuide & 모든 구매 가이드들을 구한다. \\
\cline { 2 - 3 } & FindTVGuide & 시작시간과 재생시간에 따르는 TV 가이드를 구한다. \\
\cline { 2 - 3 } & GetPurchaseGuideWithID & 주어진 참조(Reference) ID를 사용하여 구매 가이드를 구한다. \\
\cline { 2 - 3 } & FindTVGuideWithService & 시작시간과 재생시간에 따르는 (특정 채널과 연관된) TV 가이드를 구한다. \\
\cline { 2 - 3 } & FindContentWithService & 주어진 서비스 아이디와 관련된 콘텐츠를 구한다. \\
\cline { 2 - 3 } & GetSdpWithService & 주어진 서비스 ID 사용하여 모든 세션명세(session description)를 구한다. \\
\cline { 2 - 3 } & GetSdpWithContent & 주어진 콘텐츠 ID 사용하여 모든 세션명세(session description)를 구한다. \\
\hline
\end{tabular}




\section{V. 서비스가이드와 공통 인터페이스를 이용한 실험 및 검증}

\section{1. 검증을 위한 테스트 스트림 생성}

실험 및 검증을 위해 테스트 스트림을 기존의 모바일 방송용 스트림으로부터 부분 수정하여 생성하였다. 먼저, OMA-BCAST를 위한 방송정보를 레코딩 한 MPEG2 TS (Transport Stream)에서 서비스가이드의 전송과 관련된 $\mathrm{PID}$ 를 찾아 동일 PID로 전송되는 모든 IP 패킷을 분석하 여 목적지 포트별로 IP 패킷을 분리한 후 OMA-BCAST에 서 정의한 데이터 식별방법에 근거하여 중복되는 데이터 들을 제거하였는데, 이는 일반적으로 모바일 방송 서비스 는 수신기에서의 수신율을 높이기 위하여 반복적으로 서 비스를 전송하는 구조를 가지고 있기 때문이다. 중복이 없 는 순수 $\mathrm{ESG} \mathrm{XML}$ 파일집합을 얻은 후, 이를 본 논문에서 개발한 서비스가이드 스키마를 적용하여 재작성 하는 단 계를 거쳐 다시 원래의 스트림과 유사한 방식으로 재생성 하였다.

서비스가이드는 크게 서비스가이드 세션 식별부분, 서비 스가이드 구성정보부분, 실제 서비스가이드 XML 데이터 부분 등 3 가지로 구성되어 있다. 본 논문에서 서비스가이드 세션 식별부분은 기존 DVB-H와의 적응을 고려하였으며, 서비스가이드 구성정보부분과 XML 데이터 부분은 본 논 문에서 제안된 스키마를 반영하도록 하였다. 이를 위해 분 리된 IP 패킷들을 위에서 언급된 서비스가이드의 세 부분 으로 분류하였다. 그룹별로 분리된 IP 패킷 중에서 서비스 가이드 구성정보와 XML 데이터를 포함하고 있는 IP 데이 터그램을 수정하여 본 논문에서 개발한 서비스가이드 스키 마를 반영한 XML 데이터를 가진 IP 데이터그램으로 만들 었다. 이렇게 작성된 서비스가이드를 $\mathrm{A} / \mathrm{V}$ 데이터그램과 연 결시키기 위해 $\mathrm{SDP}$ 정보를 수정하여, 본 논문을 검증하기 위한 테스트 스트림을 제작하였다. 이 스트림의 처리를 위 해 서비스가이드 파싱모듈과 $\mathrm{A} / \mathrm{V}$ 추출 모듈을 작성하여 서 비스가이드에서 추출된 채널목록 중 하나의 채널을 선택하 여 이와 연결된 $\mathrm{A} / \mathrm{V}$ 를 성공적으로 재생하였다.

\section{2. 인터페이스 적용 실험 및 검증}

\section{1 채널리스트 정보 조회를 위한 인터페이스 적용 예}

그림 4는 공통 인터페이스 1계층 함수를 사용하여 채널 리스트 보기 화면을 구현한 예이다. UI에서 사용자가 채널 리스트 보기에 해당하는 동작을 실행하면, GetTotalService 함수를 호출하며 이 함수는 서비스리스트 값을 리턴하고, 각 서비스에 대해서 현재 방송하고 있는 콘텐츠들을 구해 서 채널리스트와 함께 보여준다. 이 UI는 가장 기본적인 것 이고 많이 쓰이므로, 이를 모듈화 하여 TVGuide 라는 공통 인터페이스 2계층 인터페이스로 만들었고, 이를 사용하여 채널리스트 화면을 구현하면 그림 5와 같이 FindTVGuide 만 불러주면 된다. TVguidePackage 구조체는 표 5 와 같이

그림 4. 공통 인터페이스 1계층을 통한 채널리스트 질의

Fig. 4. Channel List Query through the Common Interface Layer 1

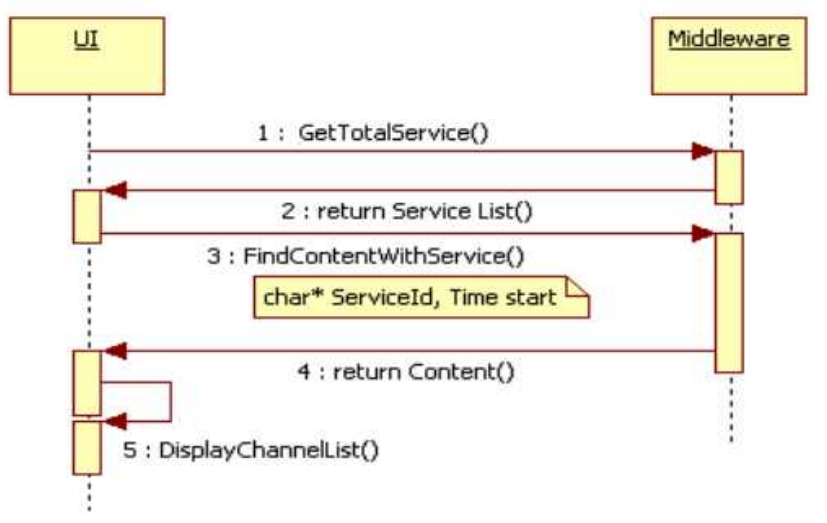

표 5. 공통 인터페이스 1계층을 통한 채널리스트 질의에 사용된 인터페이스 Table 5. Interface used for Channel List Query throuth Layer 1

\begin{tabular}{|c|c|c|}
\hline $\begin{array}{l}\text { 1. 모든 채널 } \\
\text { 정보 수집 }\end{array}$ & Get_TotalService() & $\begin{array}{l}\text { Struct TEsgService } \\
\{\text { TEsgString ilD } \\
\text { TEsgString iName } \\
\text { TUint16 iNumber } \cdots . . \text {. }\end{array}$ \\
\hline $\begin{array}{l}\text { 3. 현재 방송 } \\
\text { 정보 수집 }\end{array}$ & $\begin{array}{c}\text { FindContentWithService(ch } \\
\text { ar* Serviceld, Time start, } \\
\text { int aLength, int aFieldType, } \\
\text { int \&retCount) }\end{array}$ & 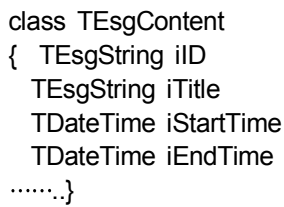 \\
\hline
\end{tabular}


서비스이름, 콘텐츠 $\mathrm{ID}$, 콘텐츠 제목 등을 함께 갖는다. 표 5 의 왼쪽 칼럼의 번호는 그림 4 의 다이어그램에서 표시된 번호를 참조하고 있으며, 리턴 받는 과정은 별도로 표시하 지 않아 1 번과 3 번만이 존재한다.

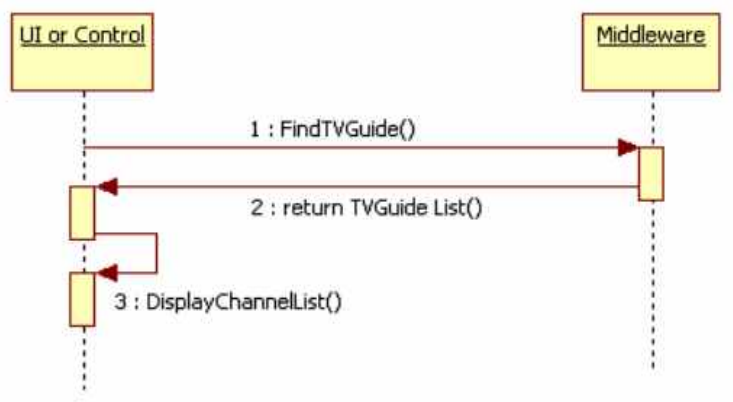

그림 5. 공통 인터페이스 2계층을 통한 채널리스트 질의

Fig. 5. Channel List Query through the Common Interface Layer 2

표 6. 공통 인터페이스 2계층을 통한 채널리스트 질의에 사용된 인터페이스 Table 6. Interface used for Channel List Query throuth Layer 2

\begin{tabular}{|c|c|c|c|}
\hline $\begin{array}{l}\text { 1. 기본 } \\
\text { Ul구성을 } \\
\text { 위한 질의 } \\
\text { 제공 }\end{array}$ & FindTVGuide() & $\begin{array}{l}\text { Struct TVGuideP } \\
\{\quad \text { WTEsgString } \\
\text { WTUint16 } \\
\text { serviceNumber } \\
\text { WTEsgString } \\
\text { WTEsgString } \\
\ldots .\}\end{array}$ & $\begin{array}{l}\text { ge } \\
\text { iceName } \\
\text { contentID } \\
\text { contentTitle }\end{array}$ \\
\hline
\end{tabular}

\section{2 프로그램 세부 정보 조회를 위한 인터페이스 적용 예} 채널리스트 화면 외에 필요한 기본적인 UI로 그림 6과 같은 프로그램 세부 정보 화면과 그림 7과 같은 시간별 프로그램 리스트 화면을 들 수 있고, TV시청 이외에는 구 매와 관련된 UI가 필요한데 이것은 전체 UI의 많은 부분 을 차지한다. 프로그램 세부정보와 프로그램 리스트 화면 을 위해서는 여러 개의 자료구조가 결합하는 것이 필요하 지 않아서 위의 서비스리스트 화면과 같이 결국에는 그림 8과 같이 FindContenWithService 로 구현이 가능한데, 단 지 이전 작업에서 프로그램 리스트를 보여주기 위한 하나 의 서비스를 선택하는 과정이나, 프로그램 세부정보를 보 여주기 위해 하나의 프로그램을 선택하는 전 과정이 필요 하다.

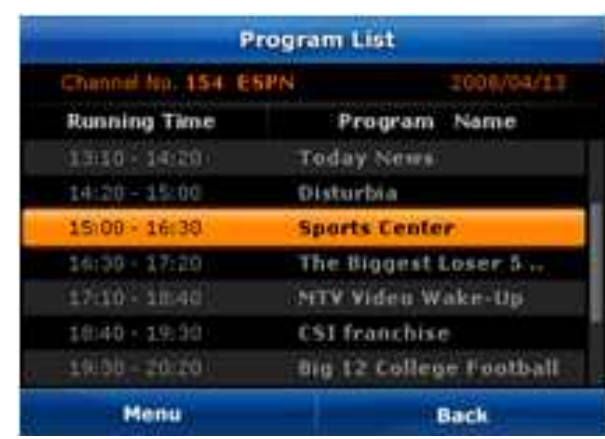

그림 6. ESG에서 추출한 서비스(채널) 리스트로 구성한 UI Fig. 6. UI constructed by Channel List fetched from ESG

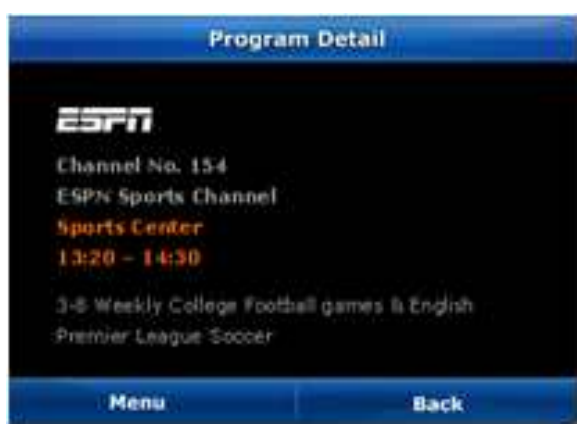

그림 7. ESG에서 추출한 프로그램 세부정보로 구성한 UI

Fig. 7. UI constructed by Program Detail fetched from ESG

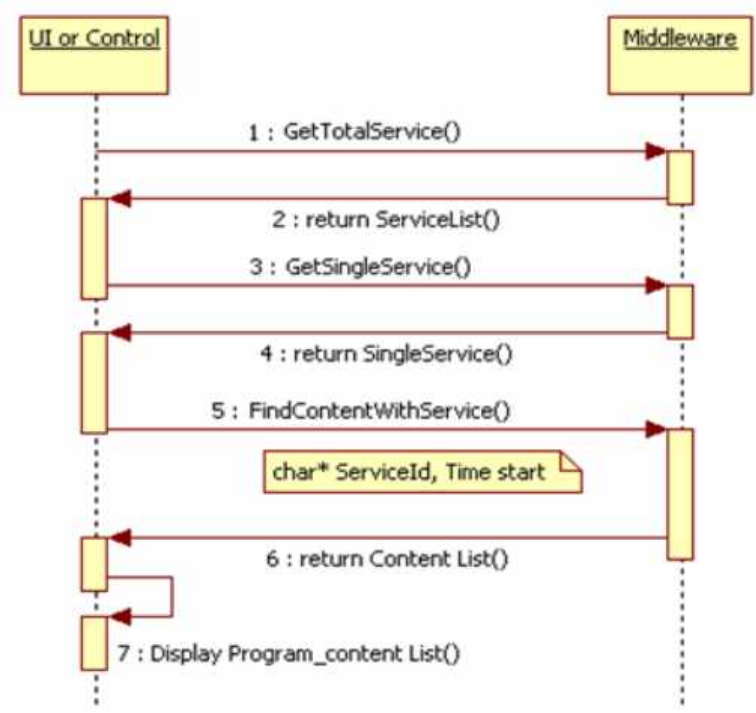

그림 8. 공통 인터페이스 1계층을 통한 프로그램 세부정보 질의

Fig. 8. Program Detail Query through the Common Interface Layer 1 
표 7. 공통 인터페이스 1계층을 통한 프로그램 세부정보 질의 Table 7. Interface used for Program Detail Query throuth Layer 1

\begin{tabular}{|c|c|c|}
\hline $\begin{array}{l}\text { 1.모든 채널 } \\
\text { 정보 수집 }\end{array}$ & GetTotalService & $\begin{array}{l}\text { Struct TEsgService } \\
\{\text { TEsgString ilD } \\
\text { TEsgString iName } \\
\text { TUint16 iNumber …... }\end{array}$ \\
\hline $\begin{array}{c}\text { 2.하나의 채널 } \\
\text { 정보 수집 }\end{array}$ & $\begin{array}{c}\text { GetSingleService(char* } \\
\text { Serviceld) }\end{array}$ & $\begin{array}{l}\text { Struct TEsgService } \\
\text { \{ TEsgString ilD } \\
\text { TEsgString iName } \\
\text { TUint16 iNumber } \cdots \cdots . . . \text {. }\end{array}$ \\
\hline $\begin{array}{l}\text { 5. 방송 정보 } \\
\text { 리스트 수집 }\end{array}$ & $\begin{array}{l}\text { FindContentWithService } \\
\text { (char* Serviceld, Time } \\
\text { start, int aLength, int } \\
\text { aFieldType, int } \\
\text { \&retCount) }\end{array}$ & $\begin{array}{l}\text { class TEsgContent } \\
\text { \{ TEsgString ilD } \\
\text { TEsgString iTitle } \\
\text { TDateTime iStartTime } \\
\text { TDateTime iEndTime } \\
\ldots \ldots . . . \\
\text { \}... }\end{array}$ \\
\hline
\end{tabular}

2.3 구매 관련 정보 접근을 위한 인터페이스 적용 예 구매 페이지는 채널 시청 권한이 없는 사용자에 대한 채 널 구매 정보 제공하는 페이지를 구성하는 것인데, 구매와
관련된 정보로는 프로그램 이름, 프로그램과 관련 된 번들 정보, 구매 비용, 구매 방법 등이 있다. 구매 시나리오는 위 에서 예로 든 채널리스트, 프로그램리스트 보다 복잡한데 이는 미들웨어와 UI 만의 인터액션이 아니라, $\mathrm{A} / \mathrm{V}$ 플레이 어에 CAS(Conditional Access System) 또는 DRM (Digital Right Management)등의 서비스보호 기능도 연동이 되어야 하기 때문이다. 기본적인 구매 시나리오는 단말에서 TV버 튼이나 메뉴 등을 사용하여 모바일 TV모드로 진입 한 후 서비스 리스트 화면에서 하나의 채널에 대한 재생을 요청 한 상태에서 시작하며 세부 단계는 다음과 같다.

(1) 해당 채널을 재생하기 위한 정보를 얻기 위해 미들웨 어에 $\mathrm{SDP}$ 정보를 요청하여, (2) SDP를 획득하면 (3)이 정 보를 통해 $\mathrm{A} / \mathrm{V}$ 플레이어에 채널 재생을 요청한다. (4) 플레 이어는 사용자가 해당 채널의 시청 권한이 있는지 확인하 여, (5) 권한이 없는 경우에는 권한 없음을 미들웨어에게 알려주고, (6) UI를 통해 사용자에게 권한 없음을 알려준다.

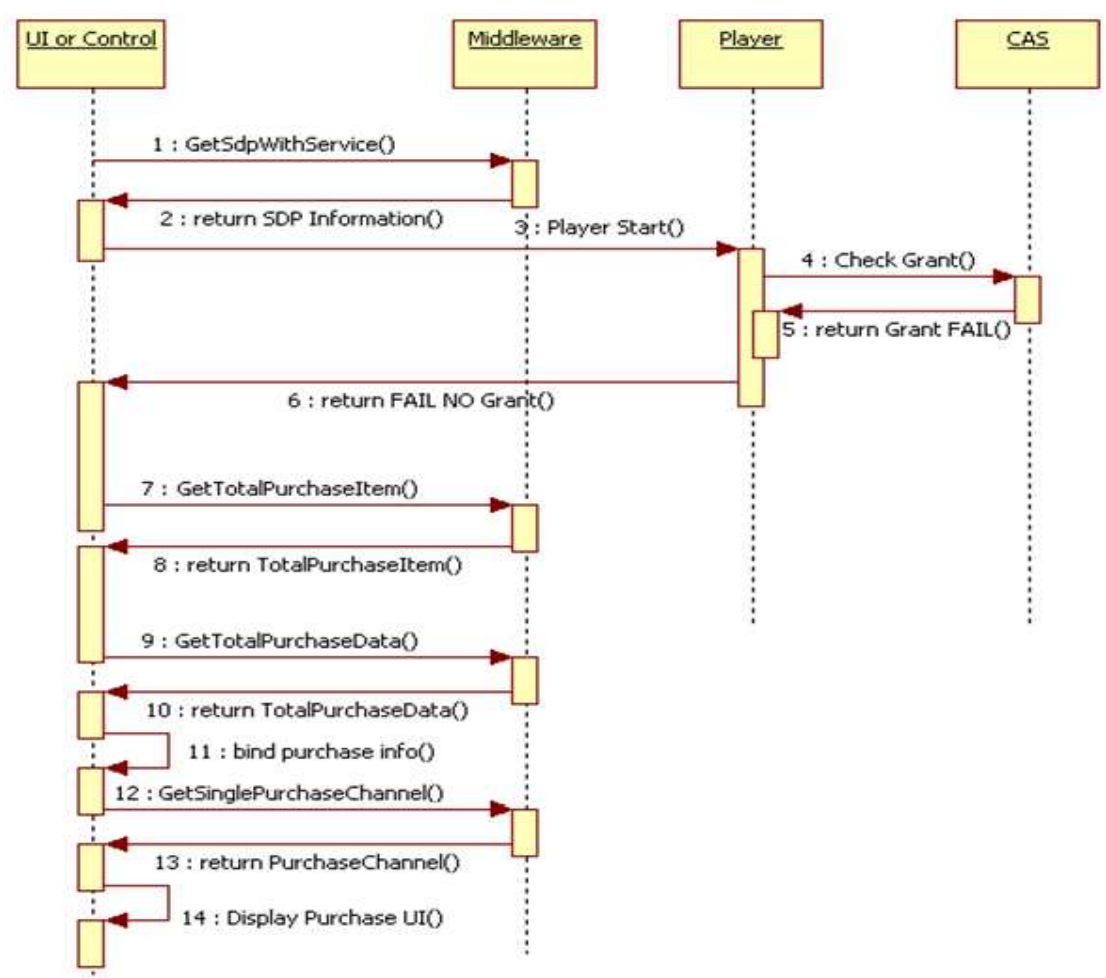

그림 9. 공통 인터페이스 1계층을 통한 구매 정보의 질의

Fig. 9. Purchase Information Query through the Common Interface Layer 1 
그러면, 구매 정보 제공을 위해 모든 구매 아이템들의 리스 트와 모든 구매 데이터들의 리스트를 요청하여 획득한다. (11) 가져온 데이터들을 조합하여 구매 채널 또는 구매 방 법이 있는지 (12) 조회하여 (13) 구매 정보를 확보한다. (14) 최종적으로 이를 사용자에게 전달한다.

이러한 전형적인 시나리오를 지원하기 위해 구매 가이드 (PurchaseGuide)를 공통 인터페이스 계층 2에 구현하였다. 즉, 계층 2의 FindPurchaseGuide 인터페이스를 사용하면, 7번 이후의 과정이 이 인터페이스를 통해 구매 UI 제공이 가능하고, 구매를 원하는 서비스 정보만으로 질의 할 수 있 도록 하였다.

\section{3. 고찰}

본 절에서는 기존 방식에 대하여 공통인터페이스를 사용 하면서 개선된 사항들을 실제 예와 수치를 사용하여 설명 한다. 유럽향 상용 휴대폰 모델에서 단일 단말에 OMA$\mathrm{BCAST}$ 와 DVB-IPDC의 두 가지 표준을 지원하여 여러 나 라에 동시에 출시하기 위해 두 종류의 미들웨어 탑재가 필 요한 사례가 있었다. 단말 상에서 모바일 $\mathrm{TV}$ 관련 모듈이 (1) 표준자체를 지원하는 미들웨어 코드, 사업자 요구사항 에 의해 단말사가 지원하는 (2) UI(User Interface) 코드, 미 들웨어와 UI를 연결하는 (3) OEM( Original Equipment Manufacturer) 코드로 구성된다고 본다면, $\mathrm{OEM}$ 인터페이 스 부분은 사용자 인터페이스와 미들웨어의 연결부분 즉, $\mathrm{UI}$ 개발을 위해 $\mathrm{ESG}$ 로부터 필요한 데이터를 질의하고 주 고받기 위한 제반 인터페이스라고 볼 수 있다. 기존의 방식 에서는 $\mathrm{DVB}, \mathrm{OMA}$ 미들웨어 공급사간의 동일 여부와 상 관없이 추가 작업을 줄이고 빠른 출시를 위해 단말에 $\mathrm{DVB}$, $\mathrm{OMA}$ 미들웨어를 각각 탑재 하였다. 복수 미들웨어가 탑재 되어 $\mathrm{OEM}$ 인터페이스를 미들웨어 별로 따로 제작하는 경 우에는 미들웨어 별로 코드가 필요하므로 코드 크기가 커 지고 작업량과 개발기간이 늘어나는 문제가 있었는데, 미 들웨어에서 공통인터페이스를 제공하면 한번의 OEM 인터 페이스 개발로 두 개의 표준을 지원할 수 있다.

공통 인터페이스의 개발을 통해 줄어든 코드의 크기는 다음과 같다. 먼저, 미들웨어에서 단말에 탑재된 미들웨어
의 바이너리의 크기는 각각 $\mathrm{BCAST}$ 가 5.3메가바이트, $\mathrm{IPDC}$ 가 6.1 메가바이트인데, 처음에는 기존 코드의 재사용 과 빠른 납기를 위해 중복 탑재되었다. 공통인터페이스를 적용하여 추가 개발된 공통모듈 코드 크기는 7.1 메가바이 트이고, OMA-BCAST와 DVB-IPDC에 사용되는 공통모듈 (IP, FLUTE 프로토콜스택 등) 이 3.8메가바이트이며, 공통 인터페이스로 인해 0.5 메가바이트 정도의 미들웨어 코드 크 기를 줄일 수 있다. OMA-BCAST와 DVB-IPDC에서 두 가 지 표준을 지원하기 위해서 미들웨어 입장에서는 FLUTE, RTP(Real-time Transport Protocol) 등의 하위 프로토콜 스 택은 동일하고 $\mathrm{ESG}$ 와, $\mathrm{SG}$ 의스키마가 다른 것이 가장 문제 였기 때문에, 서비스가이드 부분의 공통인터페이스가 결국 공통 미들웨어를 의미하게 된다.

다음으로, $\mathrm{OEM}$ 코드 크기를 줄였는데, $\mathrm{OEM}$ 코드는 서 비스가이드를 가져오기 위한 질의가 주요부분인데, $\mathrm{OEM}$ 코드 개발자 입장에서는 $\mathrm{SG}, \mathrm{ESG}$ 규격을 직접 보지 않고 도 공통인터페이스만을 참조하여 개발할 수 있으므로 이 부분의 코드 크기가 각 표준에 대해 서로 다른 구조체를 사용할 때에 비해 절반가량 감소하여 약 10 메가바이트 이 상 줄어들었다.

미들웨어와 $\mathrm{OEM}$ 코드 크기의 감소와 함께, UI 개발자와 미들웨어 포팅 작업자간의 협업 작업량이 반으로 줄어들어 제품 개발 기간을 단축시킬 수 있는 것도 개선된 점이다. 그 외에도, 각 표준에 대해 재 빌드, 리부팅 등의 절차가 필요 없이 대응 가능하고, 복수 표준에 대응하는 응용프로 그램을 작성하는 것이 가능하며, 복잡한 표준의 구조를 보 다 친숙한 형태로 제공할 수 있어서 결과적으로 응용프로 그램 작성 및 라이브러리 유지보수가 용이해 질 수 있다.

\section{VI. 결 론}

본 논문에서는 DVB-H와 OMA-BCAST를 포괄할 수 있 는 공통 서비스가이드 스키마와 이를 활용하는 공통 인터 페이스를 작성하였다. 제안된 서비스가이드 스키마는 기존 의 DVB-IPDC ESG와 OMA-BCAST SG 스키마보다 간결 하면서도 기본적인 사용자 시나리오 지원에는 문제가 없도 
록 설계 하였다. 제안된 스키마는 자체적인 서비스가이드 스키마로 사용될 수 있을 뿐 아니라, 기존의 DVB-IPDC $\mathrm{ESG}$ 와 $\mathrm{OMA}-\mathrm{BCAST} \mathrm{SG}$ 와 호환되는 핵심 자료구조로 사 용될 수 있으며, 제안된 공통 인터페이스는 단일 단말에서 다수개의 모바일 TV 규격을 지원하는 통합 미들웨어의 공 통 인터페이스로 활용될 수 있다. 제안된 스키마와 인터페 이스의 검증을 위해 본 스키마를 사용한 서비스가이드의 $\mathrm{XML}$ 을 포함하는 MPEG2 TS를 생성하여 이를 자체 제작 한 미들웨어에서 접근하여 채널목록, 프로그램 상세정보, 구매정보들을 조회하는 사용자 인터페이스를 구성하는 실험을 수행하였다. 추후, 보다 복잡한 시나리오를 지원 해야 하는 경우에는 본 논문에서 제안한 공통 스키마와 공통 인터페이스의 개념을 사용하되 스키마의 세부 엘리 먼트나 속성들의 확장과 인터페이스 함수의 추가가 필요 할 수 있다.

\section{참 고 문 헌}

[1] Open Mobile Alliance (OMA), "Service Guide for Mobile Broadcast Services- Draft Version 1.1", OMA-TS-BCAST_Service_ Guide-V1_1-20090114-D, Jan. 2009
[2] Digital Video Broadcasting (DVB), "Digital Video Broadcasting (DVB); IP Datacast over DVB-H: Electronic Service Guide (ESG)", ETSI TS 102 471, Sep. 2008

[3] http://www.bmco-berlin.com/

[4] Digital Video Broadcasting (DVB) "IP Datacast over DVB-H: Use Cases and Services", ETSI TR 102 473, Apr. 2006

[5] Open Mobile Alliance (OMA), "Mobile Broadcast Services Requirements", Open Mobile AllianceTM, OMA-RDBCAST-V1_0, Feb. 2008

[6] Digital Video Broadcasting (DVB) "IP Datacast over DVB-H: Content Delivery Protocols",ETSI TS 102 472, Dec. 2006

[7] Xu Zhang, Personalized ESG for converged digital broadcast and 3G mobile services, Technical University of Denmark, Jan. 2008

[8] Emin Gencpinar, Tolga Berber, Gamze Seckin, Adil Alpkocak, "MPEG-7 based Service Guide for Mobile TV", Proceedings of the 3rd ACM int. conf. on Mobile multimedia communications, 2007

[9] Nicolas Tondre, "FastESGTM Solutions: End-to-end management of Mobile TV \& IPTV Services, Expway, Nov. 2007

[10] Open Mobile Alliance (OMA), "Mobile Broadcast Services Architecture", Open Mobile AllianceTM, OMA-AD-BCAST-V1_020080609-C, Jan. 2008

[11] TV-Anytime forum, "Broadcast and On-line Services: Search, select, and rightful use of content on personal storage systems Part 3: Metadata; Sub-part 1: Phase 1 - Metadata schemas", Nov. 2007

[12] ISO/IEC 15938-2, Information technology - Multimedia content description interface - Part 2: Description definition language, Apr. 2002

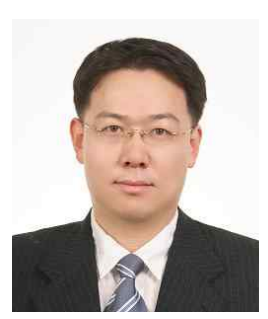

\section{김 준 환}

- 1995년 2월 : 한국과학기술원 정밀공학과(공학사)

- 1998년 2월 : 한국과학기술원 기계공학과(공학석사)

- 1998년 2월 : 전자통신연구소(ETRI) 위촉 연구원

- 2003년 8월 : 한국과학기술원 기계공학과(공학박사)

- 2006년 9월 : 미국 표준 연구소 (NIST) 연구원

- 2009년 11월 : WRG 선행기술그룹 이사

- 주관심분야 : 모바일 방송 서비스, Affective Computing

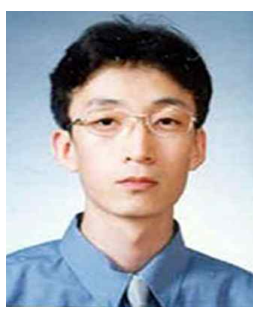

\section{장 성 만}

- 1997년 2월 : 한남대학교 수학과 (공학사)

- 2001년 2월 : 한남대학교 컴퓨터공학과 (공학석사)

- 2003년 2월 : 한남대학교 박사과정 중퇴

- 현재 : WRG 선임연구원

- 주관심분야 : 모바일 방송 서비스, DRM, CAS, Smartcard 


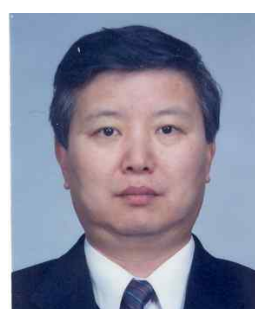

\section{정 신 일}

- 1980년 2월 : 한양대학교 전자공학과(공학사)

- 1982년 2월 : 한국과학기술원 전기 및 전자공학과(공학석사)

- 1982년 2월 현재 : 한국방송 방송기술연구소 부장

- 주관심분야 : 모바일 방송 서비스, 모바일 방송 콘텐트 보호, 디지털 방송 전송

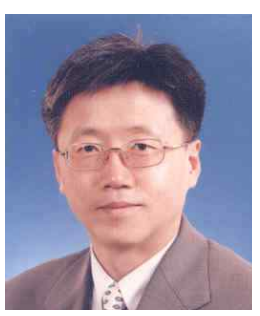

\section{경 일 수}

- 1984년 2월 : 고려대학교 전자공학과(공학사)

- 1987년 2월 : 한국과학기술원 전기 및 전자공학과(공학석사)

- 1990년 12월 : 삼성종합기술원

- 현재 : 한국방송 방송기술연구소 근무

- 주관심분야 : 멀티음향, DMB 서비스, 모바일 방송

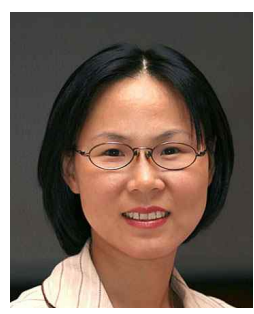

\section{김 현 순}

- 1995년 2월 : 경북대학교 전자공학과 졸업

- 1997년 2월 : 경북대학교 대학원 전자공학과 석사 졸업

- 2001년 2월 : 경북대학교 대학원 전자공학과 박사 졸업

- 2001년 7월 현재 : 한국방송 방송기술연구소 근무

- 주관심분야 : DMB 서비스, 모바일 방송 